\title{
Open Access Journal of Endocrinology
}

\section{Is it Useful to Perform FNAC in Thyroid Gland Diseases?}

\author{
Chandio $\mathrm{A}^{1 *}$, Shaikh $\mathrm{Z}^{2}$, Abbasi $\mathbf{M}^{2}$, Chandio $\mathrm{K}^{1}$ and Naqvi SA ${ }^{1}$ \\ ${ }^{1}$ Department of Surgery, North Devon Health Care Service, UK \\ 2Department of Pathology, Liaquat University of Medical \& Health Sciences, Pakistan
}

*Corresponding author: Ashfaq Chandio, Department of Surgery, North Devon Health Care Service, UK, Tel: 0044-7460444817; Email: chandioashfaq@yahoo.com

\section{Conceptual Paper}

Volume 2 Issue 2

Received Date: May 08, 2018

Published Date: June 01, 2018

\section{Abstract}

Background: Neck masses are usually benign, their clinical importance is primarily related to the need to exclude thyroid cancer Thyroid gland cancer accounts for $1 \%$ of all cancers and is responsible for $0.5 \%$ of death related to cancer. Patient age and histology as well as stage of cancer are important prognostic factors. FNAC represents a feasible, valuable screening examination.

Aim: The goal of this study was to find out the predictive value of Fine needle aspiration cytology in the evaluation of thyroid gland diseases.

Methods: This is prospective study on patient underwent FNAC because the Neck Swelling from January 2016 to December 2016. The mean age of the patients was 33.47 years (range: 15 -70) accuracy rates were evaluated.

Results: On stratification of age 50(50\%) accuracy was found to be in age group of (15-30) 35(35\%) in age group of (3135 ) and $9(9 \%)$ accuracy was found in age group of (51-70)accuracy of FNAC with respect to gender accuracy was found to be 5(71.42\%) out of 7 males and 89(95.69) out of 93 women

Conclusion: FNAC plays useful role in the preoperative investigation of the thyroid gland diseases. The experience as well as the skills of the cytopathologist in aspiration and interpretation of aspirates will improve the practice.

Keywords: Thyroid cancer; Pathology; Cytology; Sensitivity; Histology

\section{Background and Objective}

Thyroid cancer accounts for 4 to 6.5 percent of all thyroid nodules. Accurate evaluation of thyroid nodules is crucial, FNAC has been used worldwide due to simplicity, safety, inexpensive, easily performed procedure in outpatient clinics leading to correct diagnosis in $>70 \%$ of cases and to clinical approach in $>90 \%$ of the cases [1]. FNAC was first used for cytological diagnosis by Martin and Ellis [2] many studies have been carried out in the following years; however; the method has been widely used after 1952 [3]. False negative rate of less than 5\% When performed properly. FNAC is the preferred diagnostic method for the initial stage of evaluation of thyroid nodules [4]. It helps in triaging patients for conservative management or surgical intervention, despite its recognized interest, it has various drawbacks, such as incomplete aspiration, false negative and false 


\section{Open Access Journal of Endocrinology}

positive and inability to distinguish follicular adenoma from carcinoma $[5,6]$. The role of FNAC in the evaluation of thyroid nodules is now well established, and has become the initial test as it is safe and cost effective and has become a standard test. An adequate and good quality specimen is considered diagnostic or satisfactory. A benign cytological diagnosis is reported 50\%to $90 \%$ (average, $70 \%$ ) [7-9]. $10 \%$ to $30 \%$ of FNAC specimens could be suspicious for malignancy (indeterminate) (average, 20\%) [7,8]. Accurate cytological evaluation of thyroid nodules is crucial for maximizing the benefits of a medical therapy rather than the risk of an unnecessary surgery.

The goal of this study was to find out the accuracy of Fine needle aspiration cytology in the evaluation of thyroid gland diseases.

\section{Material and Methods}

A total of 100 patients referred to department of Pathology Liaquat University of Medical \& Health Sciences, Pakistan between January 2016 and December 2016 with Neck swelling were analysed prospectively for a possible diagnosis thyroid malignancy. Following information were retrieved age, gender, indications for investigations. The effectiveness and accuracy of the procedure in relation to its completeness. The diagnostic yield of pathologies (Benign/Malignant) was determined along with primary and secondary diagnosis. The sensitivity and specificity rates of cytological diagnoses were evaluated based on histopathological diagnoses. After exclusion of the no diagnostic results, cytological evaluation results were classified as positive and negative Comparing the results of cytological and histopathologic examinations, the sensitivity, specificity, positive and negative predictive value, and accuracy were calculated. Patients with no diagnostic FNAC were excluded from the calculations.

\section{Statistical Analysis}

Data were analysed using the Statistical Package for Social Sciences (SPSS, version 17). Mean values were compared using the Student $t$ test. Univariate analysis of categorical variables was performed by the chi-square test. Chi-square test was used to assess the effect of gender independent variable on the results of histopathological and cytological tests, $t$-test was performed to compare the mean age between genders. Significance of the statistical tests was based on $95 \%$ confidence interval.

\section{Results}

During the study period, hundred (100) patients were enrolled to compare the accuracy of the FNAC in the diagnosis of different categories of benign and malignant lesions with histopathology. Mean age of the patient as shown on Table 1 was 33.47 years with the standard deviation of \pm 12.10 years. The minimum age of the patient was 15 years while the maximum age was 70 years. Distribution of age with normal (Figure 1). Out of 100 patients $93(93 \%)$ were female and $7(7 \%)$ were male (Figure 2, Table 2). Accuracy of FNAC was found to be $94(94 \%)$ as shown in Figure 3, Table 3. By using chisquare test $P$ value found to be highly significant i.e. $P$ $(0.000)$ between findings of FNAC and Histopathology (Figure 4).

\begin{tabular}{|c|c|c|c|c|c|c|}
\hline \multirow{2}{*}{$\begin{array}{c}\text { Age in } \\
\text { years }\end{array}$} & 15 & 70 & 55 & 33.47 & 12.1 & $\begin{array}{c}31.06- \\
35.87\end{array}$ \\
\cline { 2 - 7 }
\end{tabular}

Table 1: Descriptive Statistics of Age $(\mathrm{N}=100)$.

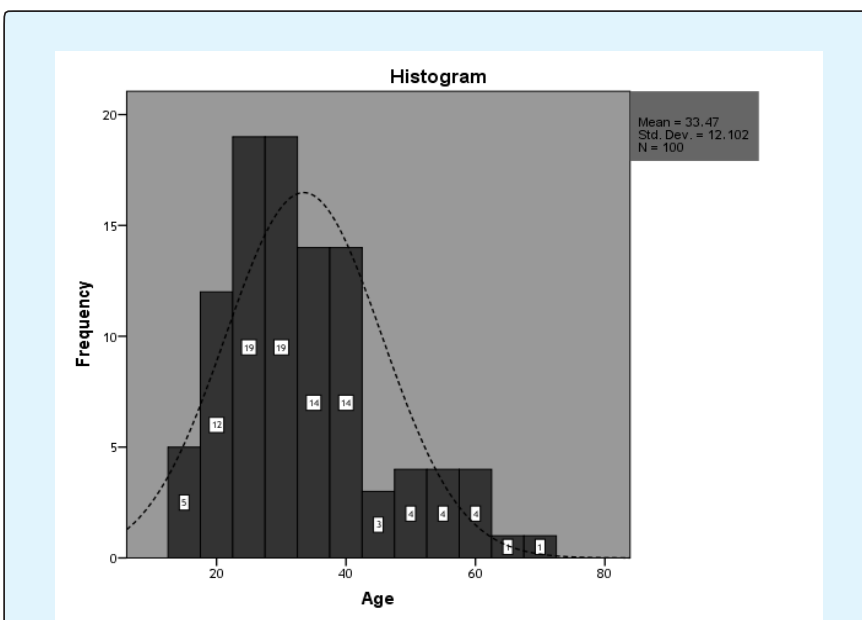

Figure 1: Graphical Presentation of Age N= (100).

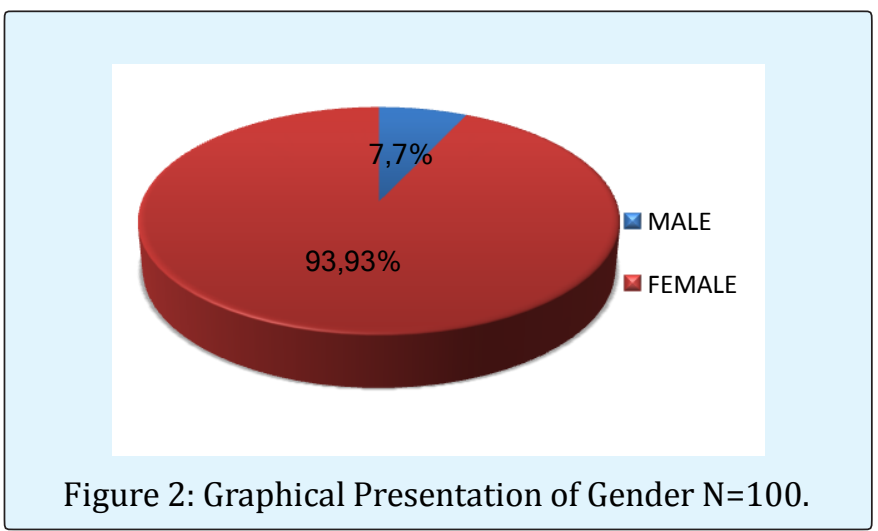




\section{Open Access Journal of Endocrinology}

\begin{tabular}{|c|c|c|}
\hline Gender & Frequency & $\mathbf{\%}$ \\
\hline Male & 7 & $7 \%$ \\
\hline Female & 93 & $93 \%$ \\
\hline
\end{tabular}

Table 2: Gender Distribution N=100.

\begin{tabular}{|c|c|c|}
\hline Accuracy & Frequency & \% \\
\hline Yes & 94 & $94 \%$ \\
\hline No & 6 & $6 \%$ \\
\hline
\end{tabular}

Table 3: Accuracy of FNAC N=100.

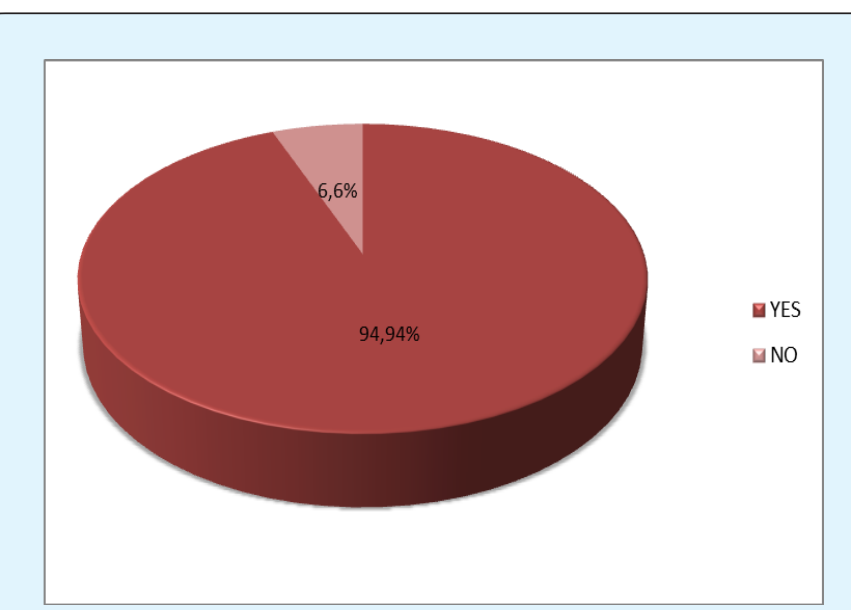

Figure 3: Graphical Presentation Of Accuracy N=100.

On stratification of age $50(50 \%)$ accuracy was found to be in age group of (15-30) 35(35\%) in age group of (3135 ) and $9(9 \%)$ accuracy was found in age group of (5170 ) by using chi-square test $P$ value found to highly nonsignificant i.e. (0.853) as shown in Figure 4, Table 4 Similarly, stratification of accuracy of FNAC with respect to gender accuracy was found to be $5(71.42 \%)$ out of 7 males and 89(95.69) out of 93 women by using Fisher's Exact test P-value was found to be slightly non-significant (Table 5). Findings of FNAC and Histopathology shown in Tables 6 \& 7.

Applying Chi-square test

\begin{tabular}{|c|c|c|c|}
\hline Age Group & \multicolumn{2}{|c|}{ Accuracy of FNAC } & \multirow{2}{*}{ P-Value } \\
\hline $15-30$ & 50 & 3 & \multirow{2}{*}{0.853} \\
\hline $31-50$ & 35 & 2 & \multirow{2}{*}{$51-70$} \\
\hline
\end{tabular}

Table 4: Stratification of Accuracy with Respect to Age Group N=100.

Applying Fisher's Exact test

\begin{tabular}{|c|c|c|c|}
\hline Gender & \multicolumn{2}{|c|}{ Accuracy of FNAC } & \multirow{2}{*}{ P-Value } \\
\hline & Yes & No & \multirow{2}{*}{0.055} \\
\hline Male & 5 & 2 & \\
\hline Female & 89 & 4 & \\
\hline
\end{tabular}

Table 5: Stratification of Accuracy with Respect to Gender $\mathrm{N}=100$.

\begin{tabular}{|c|c|c|c|}
\hline \multicolumn{2}{|c|}{ Findings } & Frequency & Percent \\
\hline \multirow{4}{*}{} & atypia/anaplastic ca** & 1 & 1 \\
\cline { 2 - 4 } & benign lesion & 5 & 5 \\
\cline { 2 - 4 } & benign Lesion & 1 & 1 \\
\cline { 2 - 4 } & benign lesion B & 15 & 15 \\
\cline { 2 - 4 } & benign lesion C & 1 & 1 \\
\cline { 2 - 4 } & benign lesion D & 1 & 1 \\
\cline { 2 - 4 } & benign lesion? & 1 & 1 \\
\cline { 2 - 4 } & benign Lesion A & 44 & 44 \\
\cline { 2 - 4 } & benign lesion B & 13 & 13 \\
\cline { 2 - 4 } & benign Lesion B & 1 & 1 \\
\cline { 2 - 4 } & benign lesion C & 10 & 10 \\
\cline { 2 - 4 } & benign lesion D & 4 & 4 \\
\cline { 2 - 4 } & bl/pap ca**** & 1 & 1 \\
\cline { 2 - 4 } & mal/pap ca*** & 1 & 1 \\
\cline { 2 - 4 } & susp/papillary ca** & 1 & 1 \\
\hline & Total & 100 & 100 \\
\hline
\end{tabular}

Table 6: Findings of FNAC N=100.

\begin{tabular}{|c|c|c|c|}
\hline \multicolumn{2}{|c|}{ Findings } & Frequency & Percent \\
\hline \multirow{4}{*}{} & atypia/anaplastic ca** & 1 & 1 \\
\cline { 2 - 4 } & benign Lesion & 1 & 1 \\
\cline { 2 - 4 } & benign lesion A+D & 1 & 1 \\
\cline { 2 - 4 } & benign lesion B & 15 & 15 \\
\cline { 2 - 4 } & benign lesion H & 1 & 1 \\
\cline { 2 - 4 } & benign lesion A & 44 & 44 \\
\cline { 2 - 4 } & benign lesion B & 14 & 14 \\
\cline { 2 - 4 } & benign lesion C & 11 & 11 \\
\cline { 2 - 4 } & benign lesion C+D & 1 & 1 \\
\cline { 2 - 4 } & benign lesion D & 5 & 5 \\
\cline { 2 - 4 } & benign lesion S & 1 & 1 \\
\cline { 2 - 4 } & bl/pap ca**** & 1 & 1 \\
\cline { 2 - 4 } & mal/pap ca*** & 1 & 1 \\
\cline { 2 - 4 } & Malignant /pap ca**** & 1 & 1 \\
\cline { 2 - 4 } & malignant/pap ca** & 1 & 1 \\
\cline { 2 - 4 } & Medullary ca**** & 1 & 1 \\
\cline { 2 - 4 } & Total & 100 & 100 \\
\hline
\end{tabular}

Table 7: Findings of Histopathology $n=100$. 


\section{Open Access Journal of Endocrinology}

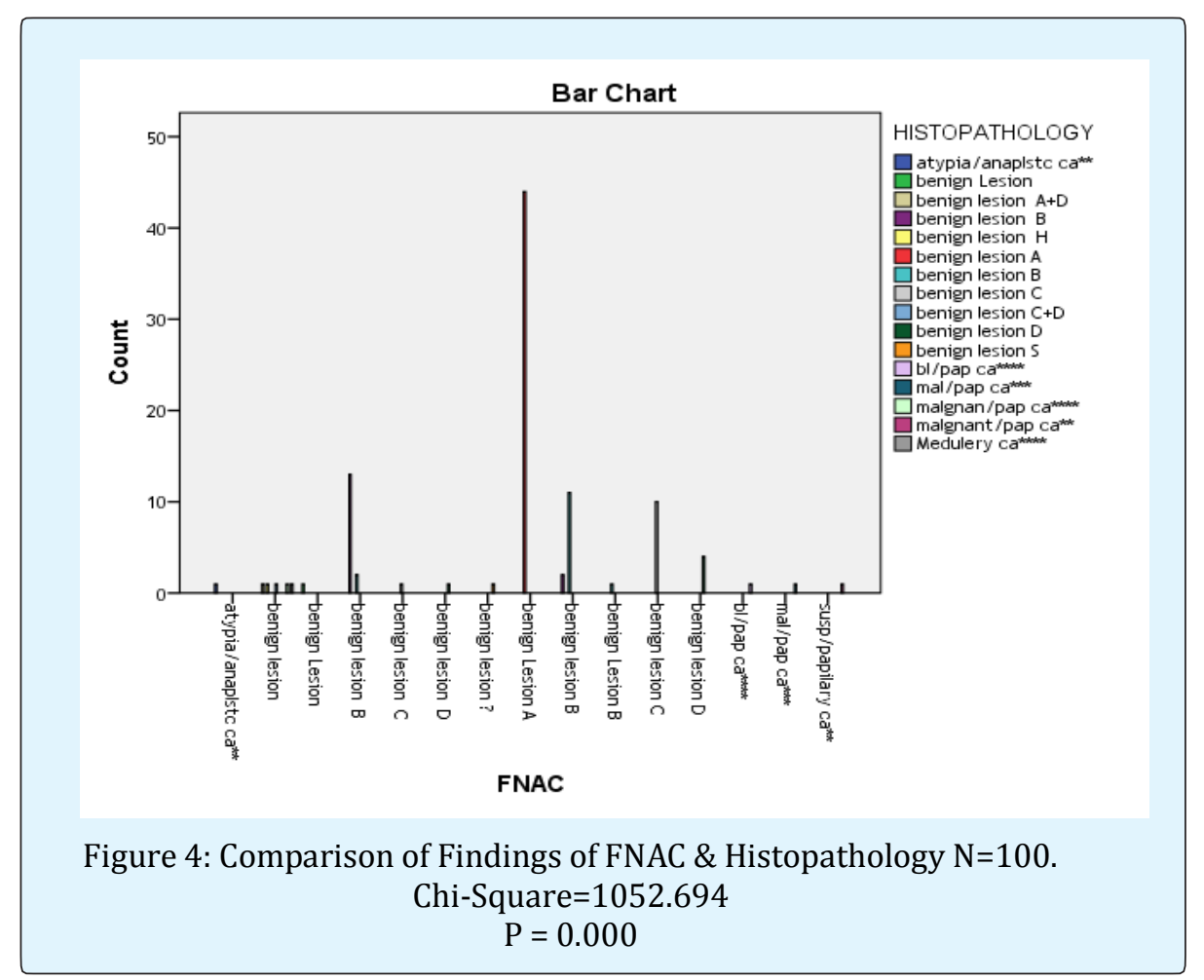

\section{Discussion}

Neck masses are usually benign their clinical importance is primarily related to the need to exclude thyroid cancer, which accounts for 4 to 6.5 percent of all thyroid nodules. Several different disorders can cause thyroid nodules [10-14]. Thyroid gland cancer accounts for $1 \%$ of all cancers and is responsible for $0.5 \%$ of death related to cancer [15]. Patient age and histology as well as stage of cancer are important prognostic factors [16]. Non-palpable nodules (incidental) have the same risk of malignancy as palpable nodules of the same size $[17,18]$. There is increasing evidence that the presence of suspicious ultrasound features is more predictive of malignancy than nodule size alone $[19,20]$. Fine-needle aspiration cytology is an easy, cost-effective test for diagnosis of cancer, its use has markedly decreased the number of unnecessary surgeries [21]. FNAC is the preferred diagnostic method for the initial stage of evaluation of thyroid nodules [4]. It helps in triaging patients for surgical intervention or conservative management, despite its recognized interest, it has various drawbacks, such as false positive and false negative, incomplete aspiration, and inability to distinguish follicular carcinoma from adenoma [5,22]. The adequacy depends not only upon the nature of the lesion but also upon the aspirator, constant practice is the only way of developing expertise. The role of FNAC in the evaluation of thyroid nodules is now well established, and has become the initial test as it is safe and cost effective and has become a standard test. An adequate and good quality specimen is considered diagnostic or satisfactory. The sensitivity and specificity ratios for FNAC in published series range between $65 \%$ and $98 \%$ for sensitivity and $73-100 \%$ for specificity [7,23-25]. In this study, we found the sensitivity of $94 \%$ this contrasts with other studies. Saddique in his study showed sensitivity of $75 \%$, specificity of $95.83 \%$ [26 ]. Kumar in his study revealed sensitivity of $77 \%$ and specificity of 100 [7].

The major reason for the wide range of sensitivity and specificity ratios is the differences in the categorization of lesion, some authors categorize follicular lesions as histopathological benign, while others categorize these lesions as malignant $[24,25,27,28]$. The factors that reduce the efficiency of FNAC include, inadequate sampling, inexperience, natural difficulties of differentiation of nature of the lesion benign and malignant follicular lesions, cellularity expected is related to the type of lesion, for example, cyst fluid may contain no thyroid epithelial cells but would still be considered adequate, where as an aspirate from a solid nodule would need to contain moderately-sized groups of epithelial cells. A benign cytological diagnosis is reported $50 \%$ to 


\section{Open Access Journal of Endocrinology}

$90 \%$ (average, $70 \%$ ) [7-9]. $10 \%$ to $30 \%$ of FNAC specimens could be suspicious for malignancy (indeterminate) (average, 20\%) [7,8]. A malignant cytological diagnosis varies from $1 \%$ to $10 \%$ (average, 5\%). Caruso and Mazzaferri [8] reported the results from 9 series that included more than 9,000 patients: benign, $74 \%$; malignant, $4 \%$; inadequate, $11 \%$; and suspicious, $11 \%$. False-negative rates generally vary from $1.5 \%$ to $11.5 \%$ (average, $<5 \%$ ) [8,29-31]. The frequency of falsenegative cytological diagnosis depends on the number of patients who subsequently have surgery and histologic review. A false-positive diagnosis indicates that a patient with a malignant FNA result was found on histologic examination to have benign lesions. False-positive rates vary from $0 \%$ to $8 \%$ (average, 3\%) [7,8,30]. Sampling errors account for false diagnoses [7,31-33]. Improper or inadequate sampling accounts for some false-negative errors, nodules smaller than $1 \mathrm{~cm}$ may be too small for accurate needle placement, and nodules larger than $4 \mathrm{~cm}$ are too large to allow proper sampling from all areas, thereby increasing the likelihood of misdiagnosis. In most retrospective series, less than $10 \%$ of patients with a benign cytological diagnosis subsequently have thyroid surgery, suggesting that false-negative rates should be interpreted with some skepticism $[7,8]$ most specialists agree that if all the patients have thyroid surgery the true false-negative rate is less than $5 \%$. False-negative rates are lower in centres with cytological interpretation by expert cytopathologists. Accurate cytological evaluation of thyroid nodules is crucial for maximizing the benefits of a medical therapy rather than the risk of an unnecessary surgery. FNAC, leading to a correct diagnosis in more than $70 \%$ of the cases in general population, represents the gold standard for achieving the appropriate management and reducing the number of benign nodules undergoing thyroid surgery [14, 34-36].

Thus, to summarise, this study found that FNAC plays a useful role in the preoperative investigation of the thyroid gland diseases. The experience, as well as the skills of the cytopathologist in aspiration and interpretation, is crucial. Fine needle aspiration is a good predictor of malignancy which results in a smaller proportion of excisions for benign nodules.

\section{References}

1. Rossi ED, Morassi F, Santeusanio G, Zannoni GF, Fadda G (2010) Thyroid Fine needle aspiration cytology processed by Thin Prep: an additional slide decreased the number of inadequate results. Cytopathology 21(2): 97-102.
2. Martin HE, Ellis EB (1930) Biopsy by needle puncture and aspiration. Ann Surg 92(2): 169-181.

3. Soderstrom N (1952) Puncture of goiters for aspiration biopsy. Acta Med Scand 144(3): 237-244.

4. Bagga PK, Mahajan NC (2010) Fine needle aspiration cytology of thyroid swellings: How useful and accurate is it? Indian J Cancer 47(4): 437-442.

5. Bajaj Y, De M, Thompson A (2006) Fine needle aspiration cytology in diagnosis and management of thyroid disease. J Laryngol Otol 120(6): 467-469.

6. Ko HM, Jhu IK, Yang SH, Lee JH, Nam JH, et al. (2003) Clinicopathologic analysis of fine needle aspiration cytology of the thyroid. A review of 1,613 cases and correlation with histopathologic diagnoses. Acta Cytol 47(5): 727-732.

7. Gharib H, Goellner JR (1993) Fine-needle aspiration biopsy of the thyroid: an appraisal. Ann Intern Med 118(4): 282-289.

8. Caruso D, Mazzaferri EL (1991) Fine needle aspiration biopsy in the management of thyroid nodules. Endocrinologist 1: 194-202.

9. Singer PA (1996) Evaluation and management of the solitary thyroid nodule. Otolaryngol Clin North Am 29(4): 577-591.

10. Werk EE, Vernon BM, Gonzalez JJ, Ungaro PC, McCoy RC (1984) Cancer in thyroid nodules. A community hospital survey. Arch Intern Med 144(3): 474-476.

11. Belfiore A, Giuffrida D, La Rosa GL, Ippolito O, Russo G, et al. (1989) High frequency of cancer in cold thyroid nodules occurring at young age. Acta Endocrinol 121: 197-202.

12. Hegedus L (2004) The thyroid nodule. N Engl J Med 351: 1764-1771.

13. Lin JD, Chao TC, Huang BY, Chen ST, Chang HY, et al. (2005) Thyroid cancer in the thyroid nodules evaluated by ultrasonography and fine-needle aspiration cytology. Thyroid 15(7): 708-717.

14. Kwong N, Medici M, Angell TE, Liu X, Marqusee E, et al. (2015) The Influence of Patient Age on Thyroid Nodule Formation, Multinodularity, and Thyroid Cancer Risk. J Clin Endocrinol Metab 100(12): 44344440 . 


\section{Open Access Journal of Endocrinology}

15. Roman SA (2003) Endocrine tumors: Evaluation of the thyroid nodule. Curr Opin Oncol 15(1): 66-70.

16. Larijani B, Aghakhani S, Haghpanah V, Mosavi-Jarrahi A, Bastanhagh M (2005) Review of thyroid cancer in Iran. Aus-Asian J Cancer 4(4): 199-203.

17. Hagag P, Strauss S, Weiss M (1998) Role of ultrasound-guided fine-needle aspiration biopsy in evaluation of nonpalpable thyroid nodules. Thyroid 8(11): 989-995.

18. Nam-Goong IS, Kim HY, Gong G, Lee HK, Hong SJ, et al. (2004) Ultrasonography-guided fine-needle aspiration of thyroid incidentaloma: correlation with pathological findings. Clin Endocrinol (Oxf) 60(1): 2128.

19. Leenhardt L, Hejblum G, Franc B, Fediaevsky LD, Delbot T, et al. (1999) Indications and limits of ultrasound-guided cytology in the management of nonpalpable thyroid nodules. J Clin Endocrinol Metab 84(1): 24-28.

20. Papini E, Guglielmi R, Bianchini A, Crescenzi A, Taccogna S, et al. (2002) Risk of malignancy in nonpalpable thyroid nodules: predictive value of ultrasound and color-Doppler features. J Clin Endocrinol Metab 87(5): 1941-1946.

21. Cibas ES, Ali SZ, NCI Thyroid FNA State of the Science Conference (2009) The Bethesda system for reporting thyroid cytopathology. Am J Clin Pathol 132(5): 658-665.

22. Ko HM, Jhu IK, Yang SH, Lee J, Nam J, et al. (2003) Clinicopathologic analysis of fine needle aspiration cytology of the thyroid. A review of 1,613 cases and correlation with histopathologic diagnoses. Acta Cytol 47: 727-732.

23. Pandey P, Dixit A, Mahajan NC (2012) Fine-needle aspiration of the thyroid: A cytohistologic correlation with critical evaluation of discordant cases. Thyroid Res Pract 9(2): 32-39.

24. Bagga PK, Mahajan NC (2010) Fine needle aspiration cytology of thyroid swellings: How useful and accurate is it? Indian J Cancer 47(4): 437-442.

25. Haberal AN, Toru S, Ozen O, Arat Z, Bilezikci B (2009) Diagnostic pitfalls in the evaluation of fine needle aspiration cytology of the thyroid: Correlation with histopathology in 260 cases. Cytopathology 20(2): 103-108.

26. Amrikachi M, Ramzy I, Rubenfeld S, Wheeler TM (2001) Accuracy of fine-needle aspiration of thyroid. Arch Pathol Lab Med 125(4): 484-488.

27. Esmaili HA, Taghipour H (2012) Fine-needle aspiration in the diagnosis of thyroid diseases: An appraisal in our institution. ISRN Pathology 2012: 4.

28. Kumar S, Aqil S, Dahar A (2008) Role of Fine Needle Aspiration Cytology in thyroid diseases. J Surg Pak 13(1): 22-25.

29. Hamburger JI (1994) Diagnosis of thyroid nodules by fine needle biopsy: use and abuse. J Clin Endocrinol Metab 79(2): 335-339.

30. Giuffrida D, Gharib H (1995) Controversies in the management of cold, hot, and occult thyroid nodules. Am J Med 99(6): 642-650.

31. Hall TL, Layfield LJ, Philippe A, Rosenthal DL (1989) Sources of diagnostic error in fine needle aspiration of the thyroid. Cancer 63(4): 718-725.

32. Solomon D (1993) Fine needle aspiration of the thyroid: an update. Thyroid today 16: 1-9.

33. Oertel YC (1996) Fine-needle aspiration and the diagnosis of thyroid cancer. Endocrinol Metab Clin North Am 25: 69-91.

34. Rossi ED, Raffaelli M, Minimo C, Mule A, Lombardi CP, et al. (2005) Immunocytochemical evaluation of thyroid neoplasms on thin-layer smears from fineneedle aspiration biopsies. Cancer Cytopathology 105(2): 87-95.

35. Fadda G, Rossi ED, Raffaelli M, Pontecorvi A, Sioletic S, et al. (2011) Follicular thyroid neoplasms can be classified as low and high risk according to HBME-1 and Galectin 3 expression on liquid based fine needle cytology. Eur J Endocrinol 165(3): 447-453.

36. Faquin WC, Baloch ZW (2010) Fine needle aspiration of follicular patterned lesions of the thyroid. Diagnosis, management and follow-up according to national cancer institute (NCI) recommendations. Diagnostic Cytopathology 38(10): 731-739. 